\title{
CFD Enhanced Thermal Spray Process for Coating of Cylinder Bores of Car Engines
}

\author{
Bernd Schilder $^{1} \cdot$ Andre Garling $^{1} \cdot$ Fabian Reimer $^{1} \cdot$ Matthias Hamann $^{1}$ \\ Rainer Joos ${ }^{1} \cdot$ Jens Hüger $^{1}$ - Matthias Pöhlmann ${ }^{1}$ - Thomas Lampke ${ }^{2}$
}

Submitted: 28 June 2019/in revised form: 10 February 2020/Published online: 12 March 2020

(C) ASM International 2020

\begin{abstract}
As the automotive industry shifts toward hybrid and alternative drive concepts like electromobility, it remains vital to continuously improve internal combustion technology. Internal combustion applications represent the largest portion of transportation technologies. Continuous development and improvement of passenger car engines focus on reducing emission by weight reduction and enhanced efficiency. To gain a competitive advantage in present and future engines, Mercedes-Benz AG developed the innovative NANOSLIDE ${ }^{\circledR}$ technology that uses thermal spray technology, i.e., twin wire arc spray, to coat the internal diameter of cylinder bores. Computational fluid dynamics (CFD) simulation is utilized to investigate the complex gas flow in the cylinder bore of the crankcase during the coating process. Extensively experiments are performed and analyzed to compare the results with the quantitative analysis in order to enhance the properties of the cylinder coating. The combination of simulation and coating experiments led to the development of uniform distributed layer adhesion strength throughout the length of the cylinder bore.
\end{abstract}

This article is an invited paper selected from presentations at the 2019 International Thermal Spray Conference, held May 26-29, 2019, in Yokohama, Japan, and has been expanded from the original presentation.

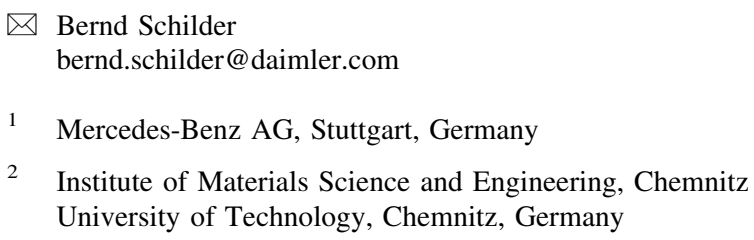

Keywords applications, adhesive strength $\cdot$ automotive computational fluid dynamics - modeling, oxidation · properties, internal diameter coating $\cdot$ twin wire arc spray

\section{Introduction}

Transportation accounts for approximately $25 \%$ of the global primary energy consumption (Ref 1 ). Road transport is responsible for more than $90 \%$ of $\mathrm{CO}_{2}$ emissions in European transport sector, and about half of these emissions are due to passenger cars (Ref 2). For this reason, it is necessary to reduce emissions. The European Union has limited the average $\mathrm{CO}_{2}$ emissions for new car fleets to $95 \mathrm{~g} \mathrm{CO}_{2} / \mathrm{km}$ by 2020 (Ref 3). In 2019, the European Parliament decided to further reduce the $\mathrm{CO}_{2}$ emission limits by $15 \%$ in 2025 and by $37.5 \%$ in 2030 compared to the fleet target in 2021. The limit values are based on the worldwide harmonized light vehicle test procedure (WLTP) (Ref 4).

In order to achieve these limits for $\mathrm{CO}_{2}$ emissions, the automotive industry develops alternative drive concepts such as hybrid technology and electromobility with battery and fuel cell. However, recent studies by the U.S. Energy Information Administration showed that in the future the internal combustion engine technology will still be the greatest portion in the transport sector (Ref 5). Therefore, the further development and improvement of the internal combustion engine are essential to increase the efficiency and thereby reduce fuel consumption and emissions. Onethird of the total energy required in the transport sector is due to friction losses (Ref 6). Approximately, a quarter of the fuel energy is used to overcome the friction in the engine (Ref 7). The most significant losses are caused by the movement of the pistons in the cylinders and are 
responsible for almost $50 \%$ of the friction losses (Ref 7$10)$.

Coating of cylinder bores is one possibility to increase the efficiency of internal combustion engines. By replacing the heavy gray cast iron liners with the typical honing structure with a thin, smooth cylinder coating, friction losses can be significantly decreased. Due to the small layer thickness of the cylinder coating, the crankcase can be downsized, thus further reducing the weight (Ref 7, 912). There are various technologies to coat the internal diameter of cylinder bores, e.g., plasma-transferred wire arc (PTWA) (Ref 13-15), rotation single wire (RSW) (Ref 16), cold spray (CS) (Ref 17), high-velocity oxygen fuel (HVOF) (Ref 12, 18) or atmospheric plasma spraying (APS) (Ref 18). The feedstock material is added to the system either as a powder (HVOF, APS, CS) or as a wire (PTWA, RSW). Thermal spray processes using wires are characterized by lower production costs and a higher production reliability compared to powder techniques (Ref 15, 19). For these reasons, Mercedes-Benz AG has developed a twin wire arc spray process (Germ. LDS) within the NANOSLIDE ${ }^{\circledR}$ technology to produce thin functional coatings in the crankcase of internal combustion engines. The advantages of the twin wire arc spray process are the high deposition rate due to the usage of two wires during the process, the efficiency and the process stability. Additionally, the design and operation of the equipment are less complex compared to other thermal spraying processes used to coat cylinder bores (Ref 7, 20). Further important aspects for the use of twin wire arc spraying in the process chain of the NANOSLIDE ${ }^{\circledR}$ technology are the low operating costs and the low heating of the substrate in comparison with other thermal spray techniques (Ref 18, 19).

\section{NANOSLIDE $^{\circledR}$ Technology}

The NANOSLIDE ${ }^{\circledR}$ technology describes the entire process chain to produce cylinder bore coatings in crankcases made of aluminum. The first step is the activation of the cylinder bore surface. A mechanical roughening process with defined cutting edges is used to create micro- and macrostructures. This surface texture is crucial for the mechanical interlocking of the coating with the substrate and therefore important for adhesion. The process is called Nissan mechanical roughening process (NMRP). Afterward, the cylinder bores are coated with an iron-carbon alloy by a twin wire arc spray process (LDS). The electric arc between the two wires melts the material, and an atomizing gas subsequently accelerates the liquid metal to the cylinder surface. The as-sprayed surface is machined by a precision turning process after the coating process to define the geometrical and positional tolerances of the cylinder bore coating. Honing is the final surface finishing step in the process chain within the NANOSLIDE ${ }^{\circledR}$ technology. This process creates the smooth, mirror-like functional surface and opens the fine pores in the coating layer that are utilized as oil retention volumes. The final thickness of the films is less than $100 \mu \mathrm{m}(\operatorname{Ref} 7,9,11)$. The thermal-sprayed cylinder bore coating decreases friction losses of the piston-liner group by up to $50 \%$ in comparison with engines using gray cast iron liners. This leads to a reduction in fuel consumption of approximately $3 \%$. Furthermore, it saves more than $4 \mathrm{~kg}$ weight (data for a V6 engine) (Ref 7, 9).

In the case of internal diameter (ID) coating of cylinder bores, the coatings must withstand the high loads during the engine operation. Therefore, the adhesion strength of coatings is an important quality feature in the field of thermal spray technology. This paper presents the latest developments on cylinder bore coatings for passenger car engines. CFD simulation in combination with coating experiments has been performed to investigate the complex gas flow in the cylinder bore during the coating process. The study shows results of the current research to enhance the adhesion strength of the coating and to improve the overall quality and efficiency of internal combustion engines produced for Mercedes-Benz Cars.

\section{Experimental Methods}

\section{Coating Experiments}

The coating experiments were carried out with a CBC200 coating system (Gebr. Heller Maschinenfabrik GmbH, Germany) which uses the twin wire arc spraying process. The spray material was 1.0479 (13Mn6) (Table 1). 13Mn6 was chosen as the spraying material because of its good surface characteristics after the honing process and therefore its remarkable tribological properties. The coating system reveals almost no signs of wear with the piston rings. In addition, the high manganese content leads to a low viscosity of the wire material in the molten state thus to a good layer formation. Furthermore, the availability of the material is high and the price of the wires is low. Nitrogen was used as the primary and secondary atomizing and shroud gas. The ratio between the flow rates of the primary and secondary gas was $3: 1$. This type of machine and the coating process are currently used in the large-scale production in Mercedes-Benz AG for coating of cylinder bores. All experiments were conducted with the crankcases for the diesel engine type OM656 (cylinder diameter $82 \mathrm{~mm}$ ) of Mercedes-Benz AG and with the process parameters used in the serial production. The aluminum alloy used for the crankcases is AlSi8Cu3. 
Table 1 Chemical composition of 1.0479 (DIN 17145) (Ref 21)

\begin{tabular}{lllllllll}
\hline Element & $\mathrm{C}$ & $\mathrm{Mn}$ & $\mathrm{Si}$ & \multicolumn{1}{c}{$\mathrm{P}$} & \multicolumn{1}{c}{$\mathrm{S}$} & $\mathrm{Cr}$ & $\mathrm{Ni}$ & $\mathrm{Cu}$ \\
\hline Min. in wt.\% & 0.08 & 1.35 & 0.30 & 0 & 0 & 0 & 0 & 0 \\
Max. in wt.\% & 0.14 & 1.65 & 0.45 & 0.025 & 0.025 & 0.12 & 0.12 & 0.17 \\
\hline
\end{tabular}

A specific mask is placed on the cylinder head sealing surface to prevent contamination of this surface by overspray and coating material during the coating process. In addition, a second mask at the lower end of the cylinder bore protects the crankshaft space from spraying material. The crankcase is fixed to a tool carrier during the coating process, which is directly connected to the extraction unit. The extraction process is necessary in order to remove overspray particles that are not embedded into the sprayed layer. Furthermore, hazardous, explosive and flammable substances may be produced during the coating process, which must be exhausted (Ref 19).

The extraction velocity was measured with a vane anemometer (Model Testo 445, Testo AG, Germany). The vane was placed centrally on top of the cylinder bore. The remaining cylinder bores of the crankcase were covered during the measurement similar to the coating process. In this study, the extraction velocity is defined as the gas velocity at the top of the cylinder bore. This parameter is automatically controlled during the coating experiments by the extraction capacity of the coating system. A portable gas analyzer (Model PG-250, Horiba, Japan) was used to measure the oxygen content in the cylinder bore. The probe was integrated in the mask that is placed on the cylinder head sealing surface of the specific bore that is coated.

\section{Characterization}

The adhesion strength of the coating on the aluminum substrate was measured by a precision adhesion tester (PAT) (Model AT101E, DFD Instruments, Norway). Test elements with a diameter of $8 \mathrm{~mm}$ are placed on the surface of the coating in the cylinder bore. Therefore, the surface of the coated cylinders is mechanically roughened by sandblasting before the test elements are bonded, in order to ensure good adhesion between the test elements and the layer in the cylinder bore. A special gun was used to uniformly and simultaneously roughen the surface of the five measurement points. The blasting material (MS 4090, iepco AG, Switzerland) has a particle size between 250 and $500 \mu \mathrm{m}$, and the operating pressure of the gun was $5 \mathrm{bar}$. The adhesive used for the measurements is a heat curing and one-component adhesive based on epoxy resin (Delomonopox ${ }^{\circledR}$ AD297, DELO Industrie Klebstoffe GmbH \& Co. KGaA, Germany). Subsequently, the adhesive is cured for $120 \mathrm{~min}$ at a temperature of $180{ }^{\circ} \mathrm{C}$.

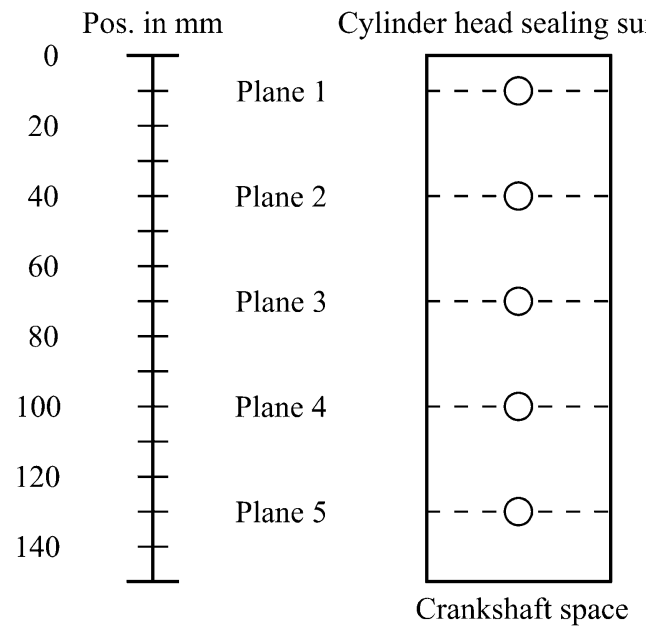

Fig. 1 Overview of the location of the measurement positions in the cylinder bore. The top of the cylinder is located at the cylinder head sealing surface, and the bottom at the crankshaft space

Afterward, the coating is milled around the test elements with a milling cutter to remove excess glue and to produce a defined measuring area. Then, the precision adhesion tester device pulls the test elements hydraulically from the coating to measure the adhesion strength. Figure 1 shows the investigated measurement planes in the cylinder bore.

The microstructural analysis of the twin wire arc sprayed coatings was performed using a scanning electron microscope (SEM) and a light microscope. Cross section specimens were cut out of the cylinder bores, embedded in resin (Allylharz Glasfiber, Presi GmbH, Germany) and polished (Swing-Plus, Microdiamant AG, Switzerland). The investigation was done with the field emission scanning electron microscope (Model Mira3, Tescan, Czech Republic) $(15 \mathrm{kV}, \mathrm{WD}=20 \mathrm{~mm})$. The image processing software ImageJ (National Institutes of Health, USA) was used to examine the microstructures in the cross sections. The microstructures of the coatings were also analyzed with energy dispersive X-ray spectroscopy (EDS) using a Quantax detector (Bruker Corporation, USA) to study the element distribution. The surface analysis of the measuring spots after the adhesion strength test was performed with the scanning electron microscope and evaluated with the image software IMS (Imagic, Switzerland). Light microscope images were taken with the Axio Observer microscope (Carl Zeiss AG, Germany). The study of the oxygen content within the coating was determined by carrier gas hot extraction method with an Eltra ONH-2000 analyzer 
(Eltra GmbH, Germany). X-ray photoelectron spectroscopy (XPS) (Model VersaProbe II, Physical Electronics $\mathrm{GmbH}$, Germany) measurements were run to investigate the oxidation kinetics of aluminum crankcases. The substrate surface was sputtered with argon ions $\left(\mathrm{Ar}^{+}, 1 \mathrm{kV}\right.$, $500 \mathrm{nA}$ ) in order to obtain depth information of the oxide layer that grows on the aluminum surfaces. The X-ray spot size was $200 \mu \mathrm{m}$.

CFD simulations were performed to gain detailed information about the gas flow during the coating process within the cylinder bore. Since the coating of cylinder bores is an internal diameter coating procedure, imaging process diagnostics can only be used to a limited extent or not at all during the coating process. Therefore, the coating process is simulated in this study. The numerical analyses were carried out with the CFD software Star-CCM+ (Siemens AG, Germany).

\section{Results and Discussion}

The investigations of this study focus on improving the adhesion strength of cylinder bore coatings, which is an important quality attribute. Since the extraction unit influences the gas flow conditions within the cylinder bore during the thermal spray process, coating experiments were performed at different extraction velocities. The mean values of the measured extraction velocities are 10.3 $\mathrm{m} / \mathrm{s} \pm 0.3 \mathrm{~m} / \mathrm{s}, \quad 8.3 \mathrm{~m} / \mathrm{s} \pm 0.3 \mathrm{~m} / \mathrm{s}, \quad 6.2 \mathrm{~m} / \mathrm{s} \pm 0.2 \mathrm{~m} / \mathrm{s}$, $4.4 \mathrm{~m} / \mathrm{s} \pm 0.2 \mathrm{~m} / \mathrm{s}$ and $2.2 \mathrm{~m} / \mathrm{s} \pm 0.2 \mathrm{~m} / \mathrm{s}$. The box plot in Fig. 2 shows the adhesion strength of the coated cylinders for various extraction velocities. The horizontal line in the box represents the median and the square the mean values of the adhesion strength. The box indicates the upper and lower quartiles of the distribution of the adhesion strength values, and the whiskers show the maximum and minimum

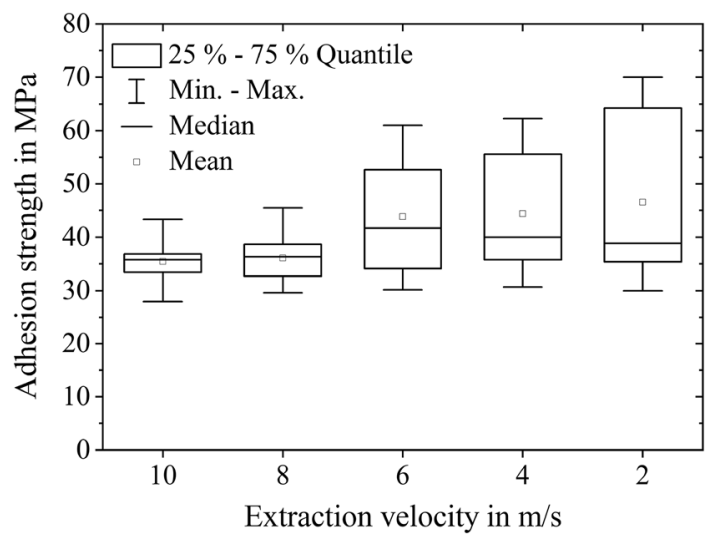

Fig. 2 Box plot of the adhesion strength for various extraction velocities during the coating process of cylinder bores (line: median, square: mean, box: $25-75 \%$ quantile and whiskers: min.-max. values) values. The minimum adhesion strength is important to ensure the quality that is required for the coating for an application in internal combustion engines. Therefore, there is a minimum tolerance limit for the adhesion strength of the coating in the production process. The higher the minimum adhesion strength of the coating, the more robust the coating becomes. In addition, the mean and maximum values represent the changes of the adhesion strength even if no change in some measurement planes took place.

The results in Fig. 2 show that the mean value of the adhesion strength increases with the reduction in the extraction velocity. The change in the extraction velocity from $10 \mathrm{~m} / \mathrm{s}$ to $2 \mathrm{~m} / \mathrm{s}$ leads to an increase in the mean adhesion strength by $31 \%$. The minimum adhesion strength values are hardly influenced by changing the extraction velocity, but there is a clear difference in the maximum values. At an extraction velocity of $2 \mathrm{~m} / \mathrm{s}$, the maximum layer adhesion increases by $59 \%$ in comparison with $10 \mathrm{~m} / \mathrm{s}$. The distribution of the adhesion strength between the lower and upper quartiles indicates that the dispersion of the values increases with the reduction in the extraction velocity. The size of the box at the extraction velocity of $2 \mathrm{~m} / \mathrm{s}$ is 6 times as large as for $10 \mathrm{~m} / \mathrm{s}$. Therefore, it is necessary to examine the influence of the extraction velocity on the adhesion strength in the respective measuring planes (Fig. 1) individually. A localized investigation is also important because it is known that the highest loads during the operation of an engine occur at the top and the bottom part of the cylinder bore (Ref 12, 22). The position of the piston rings in the upper turning point of the pistons is at measuring plane 1 . At the lower reversal point of the pistons, the piston rings are in the area close to plane 4 .

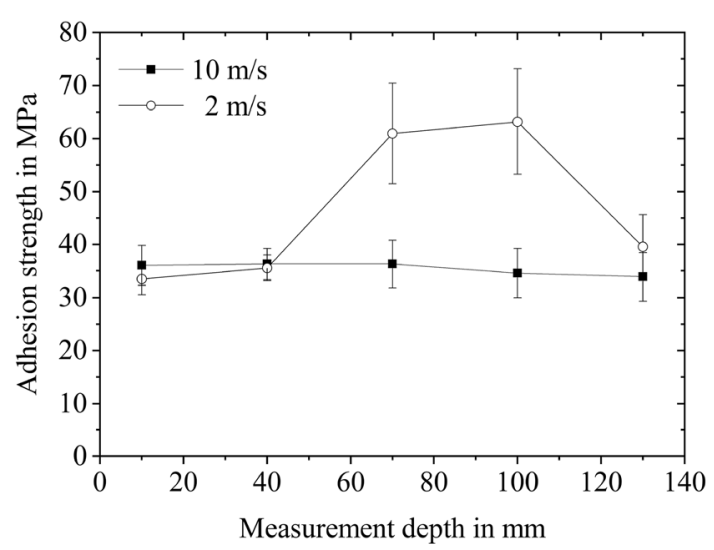

Fig. 3 Adhesion strength for high $(10 \mathrm{~m} / \mathrm{s})$ and low $(2 \mathrm{~m} / \mathrm{s})$ extraction velocities as a function of the position in the cylinder bore starting from the top of the cylinder at the cylinder head sealing surface 
Figure 3 displays the adhesion strength for the five measurement points in the cylinder bore for a high and a low extraction velocity of $10 \mathrm{~m} / \mathrm{s}$ and $2 \mathrm{~m} / \mathrm{s}$, respectively. The plot shows that the adhesion strength along the cylinder bore is almost the same in all planes for an extraction velocity of $10 \mathrm{~m} / \mathrm{s}$. At $2 \mathrm{~m} / \mathrm{s}$, a significant increase in the layer adhesion occurs in plane $3(70 \mathrm{~mm})$ and plane $4(100 \mathrm{~mm})$.

A low extraction velocity $(2 \mathrm{~m} / \mathrm{s})$ increases the adhesion of the coating by $68 \%$ in plane 3 and by $83 \%$ in plane 4 , while the adhesion strength in the upper and lower planes is almost independent of the set velocity of the extraction unit. The increase in the center of the cylinder bore results in a wider dispersion of the measured values at low extraction velocities as shown in Fig. 2. These high values also lead to the increase in the mean adhesion strength by $31 \%$ with the reduction in the extraction velocity from 10 to $2 \mathrm{~m} / \mathrm{s}$. The analysis along the length of the cylinder bore reveals that a reduction in the extraction velocity leads to a significant improvement in the coating adhesion at the high loaded lower turning point of the piston (plane 4). The following section describes the results of the numerical analysis of the process in order to gain further insights about the internal diameter coating process to explain the variations of the coating properties.

\section{Numerical Approach to Analyze the Influence of Extraction Velocity and the Position of the Burner}

To analyze the difference in the adhesion strength due to the change of the extraction velocity (Fig. 2), extensive CFD simulations have been carried out to investigate the gas flow during the coating process. The coating system CBC200 used during the coating experiments, including the extraction unit, burner system, masking concept and crankcase type OM656, was modeled for the simulations. Polyhedral cells are used to describe the flow domain. The major mesh parameters as well as the solver settings for the simulation are shown in Table 2. All simulations were performed with Reynolds-Averaged Navier-Stokes equations (RANS) before shifting to transient solver settings (unsteady Reynolds-Averaged Navier-Stokes-URANS) with a full rotating burner domain (rigid body motion). Figure 4 shows the geometry and the simulation domain for the numerical approach in detail.

The simulation considers the air flow, the nitrogen gas flow of the process gas and the spray particles. In order to obtain the most information of the flow phenomena during the coating process, the fluid domain includes a major part of the coating chamber, the crankcase, the internal burner flow and the extraction unit of the $\mathrm{CBC} 200$ coating system. As boundary conditions, the outlet mass flow, the nitrogen
Table 2 Major simulation settings

\begin{tabular}{ll}
\hline Mesh settings & \\
\hline Base size & $2.00 \mathrm{~mm}$ \\
Local refinement & $0.05-10.0 \mathrm{~mm}$ \\
Prism layer thickness & $0.65 \mathrm{~mm} / 1$ layer \\
Refinement & Burner, orifice, spray \\
Simplification & Gaps, second outlet \\
Cell count & 4.93 million \\
\hline Physics settings & \\
\hline Gas & Ideal gas equation, constant specific heat \\
& capacity and viscosity \\
Turbulence & k-epsilon-model \\
Add. models & Multi phase model, multi component model \\
Movement & Rigid body motion, const. rotation rate \\
Spray & Start velocity $40 \mathrm{~m} / \mathrm{s}, 2$-way modeling \\
Crankcase & Const. surface temperature \\
Time step & $3.0 \times 10^{-6} \mathrm{~s}$ \\
Simulation & $0.5 \mathrm{~s}$ \\
time & \\
\hline
\end{tabular}

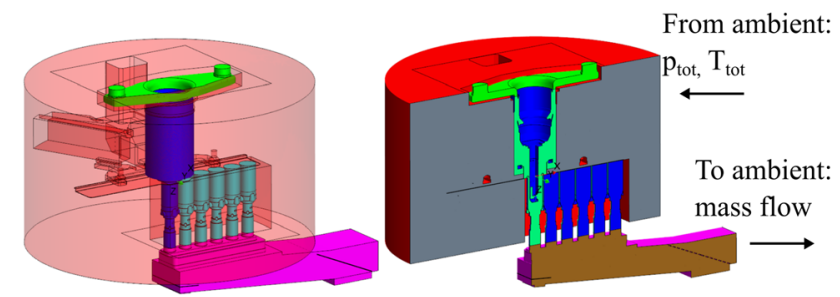

Fig. 4 Geometry and simulation domain for numerical investigations on the coating process of cylinder bores in crankcases. Visualization of the major boundary conditions

gas inlet mass flow, the total temperature and pressure inside the coating chamber, the temperature of the crankcase surface, the rotational speed of the burner and the particle mass flow are given according to measurement results. The vertical movement of the burner is neglected since its velocity is slow in comparison with the circumferential velocity. Figure 5(a) represents the two simulated axial positions of the burner. A volumetric energy source defined at the melting zone at the tip of the two wires is used to model the melting process at the burner nozzle (Fig. 5b). Since particle mass flow and the electrical power of the burner are given, a simplified model can be used to calculate the mass and the temperature of the particles at the burner nozzle. The model is calibrated with experimental results from image analysis of the particle jet during the coating process with the SprayWatch 2S system (Oseir 


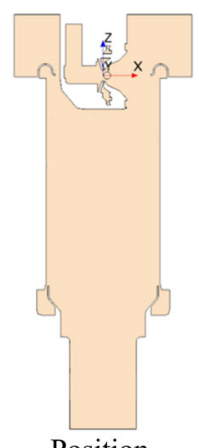

Position

(a) $20 \mathrm{~mm}$

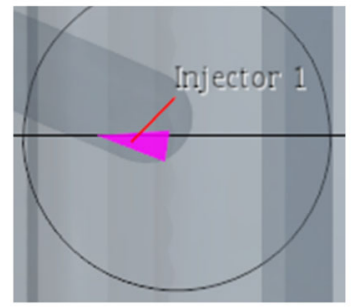

Injector

(c)

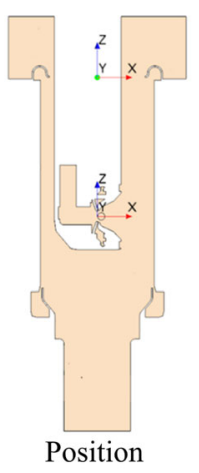

$100 \mathrm{~mm}$

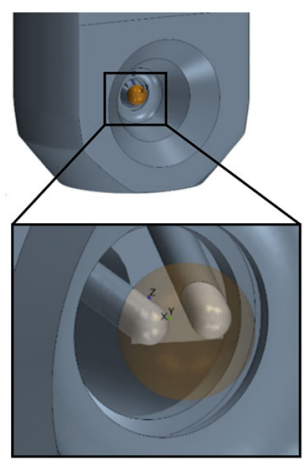

(b) Volumetric heat source
Fig. 5 (a) Different axial burner positions. (b) Definition of the burner nozzle with a volumetric heat source and melting zone and (c) calibration of the particle injector

Ltd., Finland) to fit the injector angle, position and the particle temperature (Fig. 5c).

A mesh and a solver study was performed to rate the accuracy of the simulation model. Due to rarely low Mach numbers within the main air flow domain, the experiencebased mesh settings of the air are not critical and the solution can be estimated as mesh independent. However, the flow within and close to the burner (nitrogen, ambient air, particles) shows highly complex physics which led to various investigations on the mesh settings. Figure 6 shows the property of the nitrogen flow for different mesh refinements (coarse-Fig. 6a) and indicates the importance of a fine mesh resolution (Fig. 6b) due to high Mach numbers. Similarly, the high flow velocities result in increased requirements on the time discretization. Figure 6(d) illustrates the convergence of the mass flow for different time steps. It shows a good model accuracy for a time step of $3 \times 10^{-6} \mathrm{~s}$. By considering the minimum solution time for a sufficient convergence for each simulation combined with a total cell number of 4.9 million, a simulation time of approximately $10,000 \mathrm{CPUh}$ per geometry variant results.

The simulation was performed for two different vertical positions of the burner $(20 \mathrm{~mm}$ and $100 \mathrm{~mm})$ and for two different air mass flow rates, which were calibrated to measurements with a vertical velocity in the cylinder bore of $2 \mathrm{~m} / \mathrm{s}$ and $10 \mathrm{~m} / \mathrm{s}$. Figure 7 illustrates the influence of

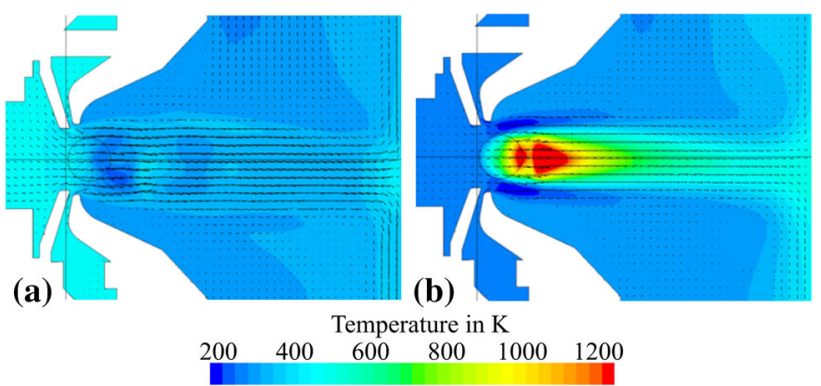

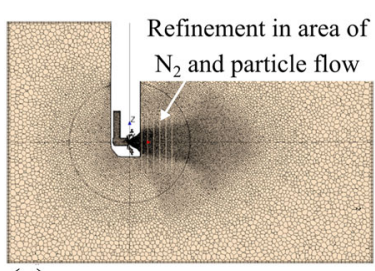

(c)

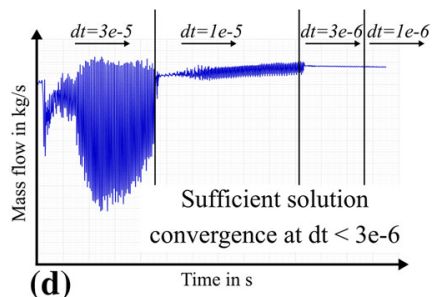

(d)
Fig. 6 Mesh study with a (a) coarse and a (b) refined mesh at the burner outlet. (c) Final mesh configuration and (d) study of minimum requirements with respect to time discretization

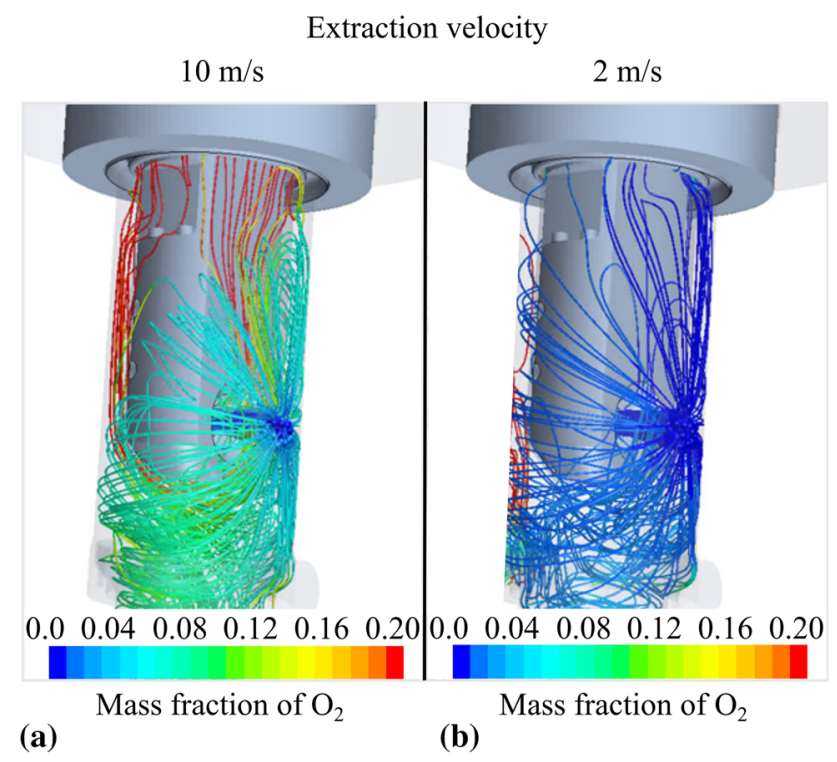

Fig. 7 Simulation of oxygen and nitrogen gas flow illustrated with streamlines that display the mass fraction of $\mathrm{O}_{2}$ depending on the extraction velocity (position: $100 \mathrm{~mm}$ )

the extraction velocity on the oxygen mass fraction within the cylinder bore at the position of $100 \mathrm{~mm}$. The simulation reveals that a high extraction velocity $(10 \mathrm{~m} / \mathrm{s}-$ Fig. 7a) results in a gas flow that draws ambient atmosphere, which contains approximately $21 \mathrm{vol} \%$ oxygen into the cylinder bore. The nitrogen gas flow emanating from the burner nozzle is used to atomize the molten spray material and to shroud the particle jet. This gas flow spreads in all directions when it hits the cylinder wall. A high portion of the upward nitrogen flow is forced 
downward by the extraction system and by the ambient air flowing in from the top of the cylinder bore. This condition leads to an intermixing of ambient air and the process gas nitrogen. The downward-directed and oxygen-enriched gas flow passes the particle jet which leads to an oxidation of the molten spray particles. The oxidation of the particles can occur during flight phase and after the impact on the substrate (Ref 13, 23, 24). In contrast to the extraction velocity of $10 \mathrm{~m} / \mathrm{s}$, the oxygen mass fraction in the system and especially close to the coating area is significantly reduced when the extraction unit is set to $2 \mathrm{~m} / \mathrm{s}$ (Fig. $7 \mathrm{~b}$ ). The nitrogen gas fills the cylinder bore and surrounds the spray particles at the position of $100 \mathrm{~mm}$.

The results from the adhesion strength measurements along the length of the cylinder bore from Fig. 3 show that in addition to the influence of the extraction velocity, there is a local dependence of the coating adhesion, which is also investigated by CFD simulations. Figure 8 visualizes the simulation results for the two different positions of the burner within the cylinder bore at a constant extraction velocity of $2 \mathrm{~m} / \mathrm{s}$.

The simulation data display a distinct influence of the burner position on the oxygen content in the system. The $20 \mathrm{~mm}$ position has a significantly higher oxygen mass fraction within the cylinder bore and around the spray particles in comparison with that at the $100 \mathrm{~mm}$ position. Due to the flow conditions in the upper position, ambient atmosphere flows into the cylinder bore and interacts directly with the process gas nitrogen emanating from the burner nozzle. This gas flow encloses the particle jet whereby the molten spray particles are exposed to the oxygen rich atmosphere. These results indicate that there

Position
$20 \mathrm{~mm}$

(a) Mass fraction of $\mathrm{O}_{2}$

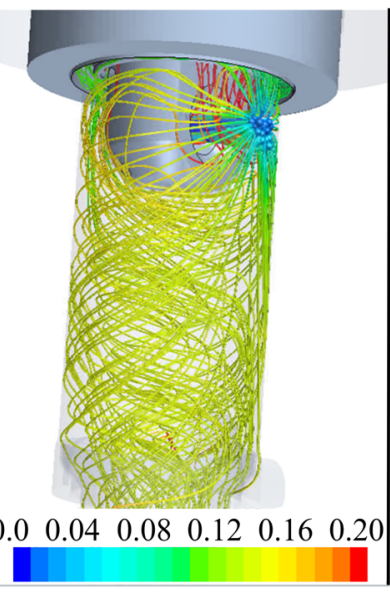

$100 \mathrm{~mm}$

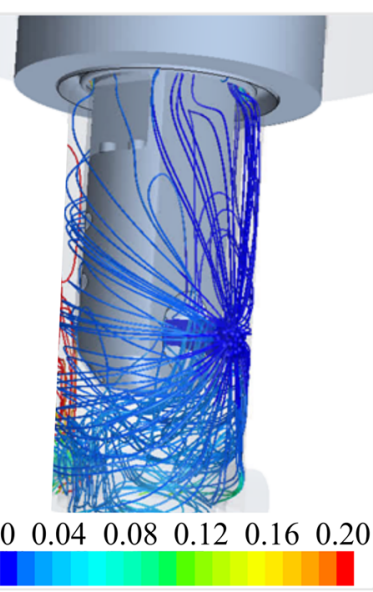

(b) Mass fraction of $\mathrm{O}_{2}$
Fig. 8 Simulation of oxygen and nitrogen gas flow illustrated with streamlines that display the mass fraction of $\mathrm{O}_{2}$ depending on the position of the burner in the cylinder bore may be increased oxidation of the spray particles in the upper position compared to the middle of the cylinder bore. It is known from the literature that the oxidation of the molten spray particles during the flight phase highly depends on the entrainment of surrounding air into the particle jet (Ref 23, 25, 26).

\section{Microstructural Analysis}

In order to investigate the microstructure of the coating and the bonding mechanism at the interface between the substrate and the coating, cross sections are made from the cylinder bore. The cross sections were examined with a light microscope. The images show the typical texture with micro- and macrostructures produced by the NMRP process. Due to the specific process control, the chip always breaks in different positions during this roughening procedure. Figure 9 presents an example of a mechanically roughened cylinder bore surface with the typical grooves and undercuts. It also demonstrates that the undercuts are irregularly distributed along the activated surface. As a result, the cross sections partially show larger and smaller roughening structures.

Figure 10 displays the light microscope images of two cross sections for an extraction velocity of $10 \mathrm{~m} / \mathrm{s}$ (Fig. 10a) and $2 \mathrm{~m} / \mathrm{s}$ (Fig. 10b). The specimens were cut out of the cylinder bore at the position of $10 \mathrm{~mm}$ below the cylinder head sealing surface in the same plane next to the adhesion test measurement spot. The activated surface of the aluminum crankcase is at the bottom of the light microscope images. On top of the substrate is the twin wire arc sprayed coating. The coatings were, respectively, honed after the coating process, resulting in the smooth surfaces. The black area in the upper part of the images represents the resin in which the cross sections were embedded. The cross sections of the thermal spray coatings show porous and lamellar structures. This morphology is typical for metallic coatings produced by wire arc spraying processes (Ref 19, 27-29). The undercuts and grooves of the

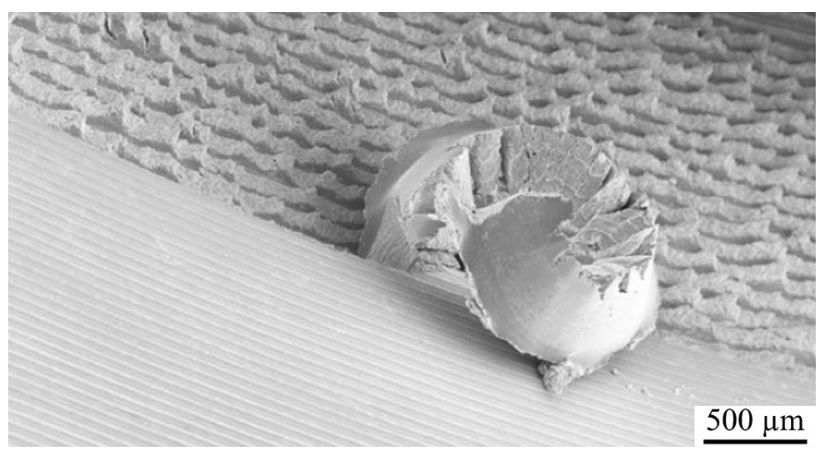

Fig. 9 Surface of an activated aluminum cylinder bore with the NMRP process 


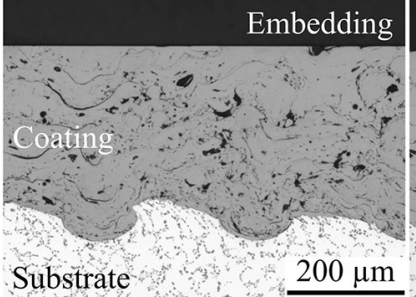

(a)

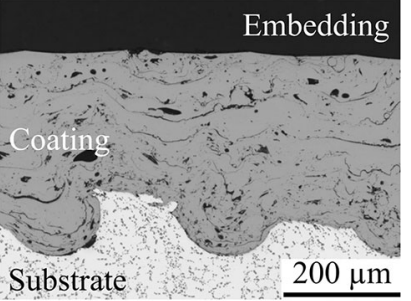

(b)
Fig. 10 Light microscope images of cross sections from twin wire arc sprayed coatings at the position of $10 \mathrm{~mm}$. The extraction velocity during coating process was (a) $10 \mathrm{~m} / \mathrm{s}$ and (b) $2 \mathrm{~m} / \mathrm{s}$

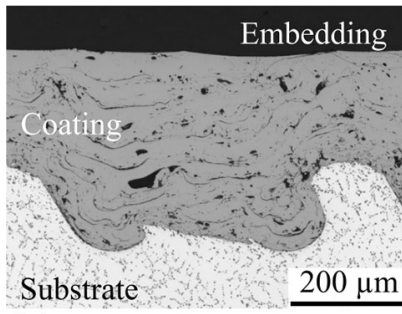

(a)

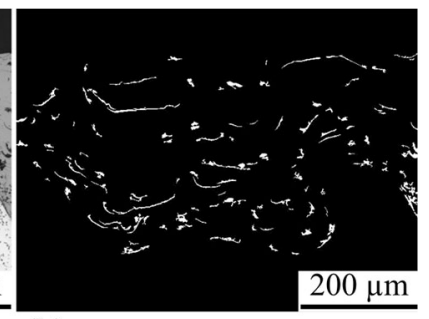

(b)
Fig. 11 Image analysis to investigate the lamellar microstructure of the coating. (a) Cross section of the coating and (b) determined microstructure

roughened substrate are all well filled with the coating material. The dark areas in the cross sections correspond to pores and oxides.

Both coating specimens cut out from plane $1(10 \mathrm{~mm})$ within the cylinder bore show comparable microstructures. They each have a considerable amount of oxides and pores within the layer. The oxides within the coating cause individual splats to be separated by oxide layers (Ref 23, 31). In order to obtain quantitative information of the microstructures of the cross sections, the images of the coatings were evaluated with an image analysis software. Therefore, the images were segmented into substrate, embedding and coating. The structures within the segmented coating were selected by an 8-bit grayscale analysis and converted into a binary graphic. Afterward, the lamellar structures were analyzed in the binary maps by characterizing and filtering the patterns according to their specific area and circularity. This enables the determination of the area of the splat boundaries and lamellar structures within the coating. Figure 11 shows an example of a cross section and its corresponding image that represents the analyzed lamellar structure in white. The proportion of lamellar structure in Fig. 10 is $3.9 \% \pm 0.2 \%$ for the sample coated with an extraction velocity of $10 \mathrm{~m} / \mathrm{s}$ and $4.3 \% \pm 0.2 \%$ for the layer sprayed with $2 \mathrm{~m} / \mathrm{s}$ extraction velocity.

Figure 12 shows the cross sections from position $100 \mathrm{~mm}$ within the cylinder bore. At an extraction velocity

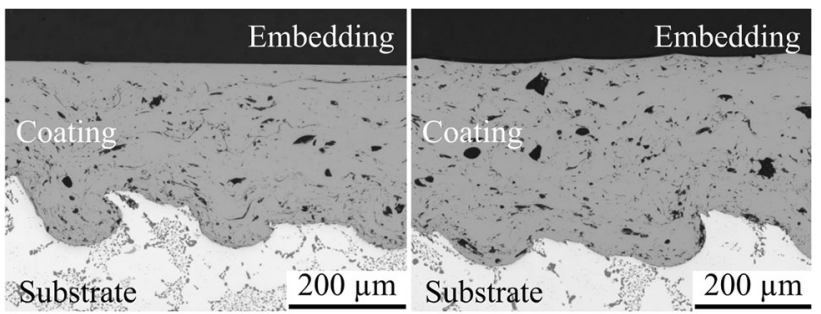

(a)

(b)

Fig. 12 Light microscope images of cross sections from twin wire arc sprayed coatings at the position of $100 \mathrm{~mm}$. The extraction velocity during coating process was (a) $10 \mathrm{~m} / \mathrm{s}$ and (b) $2 \mathrm{~m} / \mathrm{s}$

of $10 \mathrm{~m} / \mathrm{s}$ (Fig. 12a), the porous and lamellar microstructure is still present. The lamellar structure for the coating sprayed at the lower extraction velocity of $2 \mathrm{~m} / \mathrm{s}$ (Fig. 12b) is less pronounced $(1.4 \% \pm 0.3 \%)$ in comparison with the coating structure sprayed with the higher extraction velocity condition $(3.6 \% \pm 0.2 \%)$. Furthermore, the connection of the individual splats within the layer is more homogenous for the low extraction velocity than for the high extraction velocity. When the molten spray particles hit the substrate and form the coating, the splats bond better together at an extraction velocity of $2 \mathrm{~m} / \mathrm{s}$.

The results of the analysis from Fig. 3 show that there is almost no difference in the adhesion strength depending on the position within the cylinder bore at an extraction velocity of $10 \mathrm{~m} / \mathrm{s}$. The cross sections at position $10 \mathrm{~mm}$ (Fig. 10a) and position $100 \mathrm{~mm}$ (Fig. 12a) have both a microstructure with comparable percentages of interlamellar structures in the layer. In comparison, the cross section in Fig. 12b displays a more homogeneous layer structure with less pronounced oxide bands. Coating in an oxygen-free atmosphere allows the molten spray particles to hit on non-oxidized splat surfaces. The impinging particles can bond with the already solidified splats by melting their surfaces. In addition, diffusion processes between the individual splats can also take place (Ref 23). Both features lead to a homogeneous layer structure. The differences in the microstructures are presumably responsible for the fact that the adhesion strength in plane $4(100 \mathrm{~mm})$ at $2 \mathrm{~m} / \mathrm{s}$ extraction velocity is more than $80 \%$ higher than the one at $10 \mathrm{~m} / \mathrm{s}$. The CFD simulations for an extraction velocity of $10 \mathrm{~m} / \mathrm{s}$ from Fig. 7 also indicate that during the coating process in plane 4 an increased oxygen content prevails within the cylinder bore around the particle jet. The oxygen can cause the molten particles to oxidize during flight and after impact on the surface of the substrate (Ref 23).

Chips were milled from the coating and analyzed by carrier gas hot extraction method to analyze the oxygen content in the coating. The results show that the coating has different oxygen contents depending on the position within the cylinder bore. There is a more than three times higher 
oxygen content in the upper part (oxygen content in plane 1 and plane 2: $0.19 \% \pm 0.01 \%$ ) of the cylinder bore compared to the middle of the cylinder bore (oxygen content in plane $4: 0.06 \% \pm 0.01 \%$ ). A detailed EDS study of the microstructure shows also different compositions of the coating. Figure 13 presents the analyzed areas and the corresponding spectra. Oxygen was determined at the edges of lamellar structures (Fig. 13a-1) and along splat boundaries (Fig. 13b-3). In contrast, no oxygen could be detected in homogeneous areas of the cross sections (Fig. 13a-2). The two methods demonstrate that there is a higher oxygen content in the coating in the areas with low adhesion strength and that oxygen is located mainly at lamellar structures and splat boundaries.

In the literature, oxides are often considered as defects which have a negative influence on the mechanical properties of the coating. They are brittle and have a different thermal expansion coefficient than the surrounding metal (Ref 27, 30). Oxide bands at the interface of splats can also influence the cohesion between individual splats (Ref 23, 31). An increased oxide content within the sprayed layer thus can reduce the interlamellar bonding of the coating (Ref 27). As a result, the molten particles do not bond with each other when they hit the oxide surface and a layer with numerous interfaces is formed.

The cross sections in Fig. 14 display the microstructure of the coating in plane $2(40 \mathrm{~mm})$ and plane $3(70 \mathrm{~mm})$ for an extraction velocity of $2 \mathrm{~m} / \mathrm{s}$. The structure in plane 3 contains fewer interfaces between the splats within the layer. Plane 2 has a proportion of lamellar structure of $4.2 \% \pm 0.2 \%$ in comparison with plane 3 with

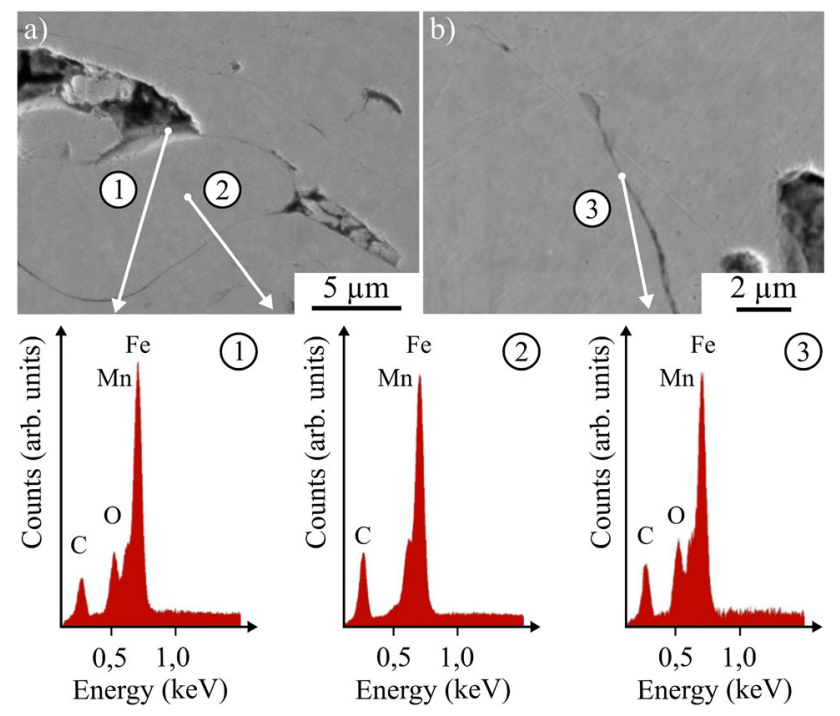

Fig. 13 EDS analysis of the microstructures from cross sections at (a) lamellar structures, homogeneous areas and (b) at splat boundaries with corresponding spectra
$2.2 \% \pm 0.2 \%$. The adhesion strength also increases from plane 2 to plane 3 by $69 \%$.

The results indicate that the oxygen mass fraction in plane 2 is higher than in plane 3 , and therefore, a local dependence of the oxygen content along the length of the cylinder bore exists. Figure 15 shows the adhesions strength and the proportion of lamellar structures along the cylinder bore. The diagram reveals that the microstructure of the coating influences the adhesion strength. Fewer boundaries within the coating result in better interlamellar bonding between the individual splats and thereby to a higher cohesion strength.

Besides the interaction between the individual splats in the layer, the interaction of the splats with the substrate also influences the adhesion strength. Therefore, the bonding between the layer and the substrate was also investigated. The measurement spots of the adhesion strength test were analyzed with the scanning electron microscope to obtain the remaining coating on the substrate after the adhesion strength measurement. The size of the base area is defined by the circular edge that was previously milled into the layer for the adhesion strength

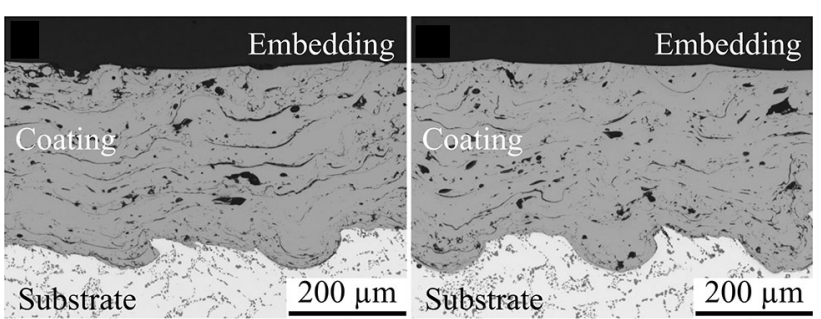

(a)

(b)

Fig. 14 Light microscope images of cross sections from twin wire arc sprayed coatings with an extraction velocity of $2 \mathrm{~m} / \mathrm{s}$ at position (a) $40 \mathrm{~mm}$ and (b) $70 \mathrm{~mm}$

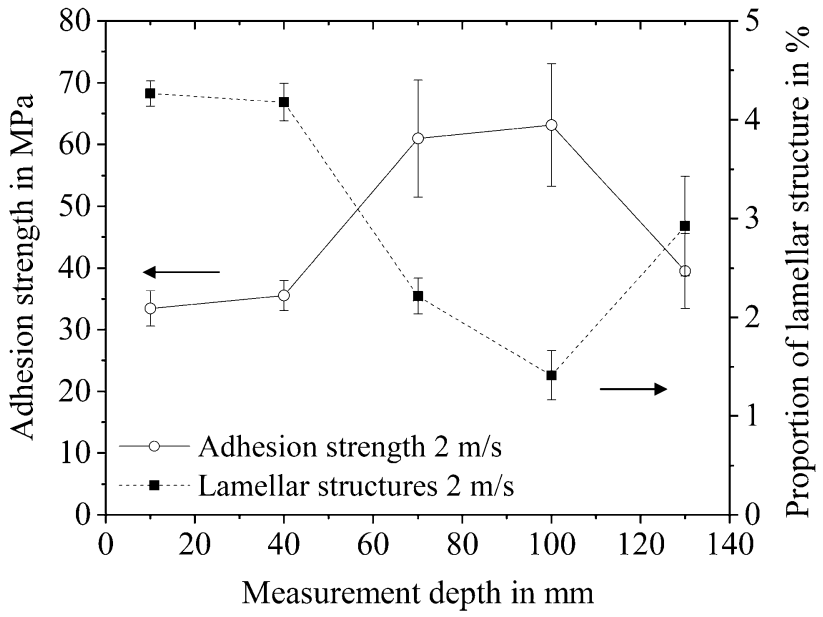

Fig. 15 Adhesion strength and proportion of lamellar structures in the coating as a function of the position in the cylinder bore for an extraction velocity of $2 \mathrm{~m} / \mathrm{s}$ 


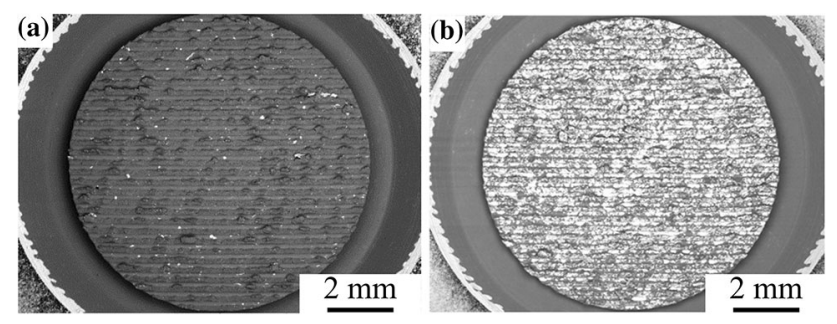

Fig. 16 SEM image analysis of the remaining coating on the aluminum substrate after adhesion strength test. Coating coverage (a) $1 \%$ (adhesion strength $=12 \mathrm{MPa}$ ) and (b) $56 \%$ (adhesion strength $=51 \mathrm{MPa}$ )

measurement (PAT). Figure 16 displays two surfaces with different proportions of remaining coating. The areas appearing bright in the SEM images are coating residues adhering to the NMRP roughened substrate surface.

In Fig. 16(a), the proportion of the remaining coating on the substrate is $1 \%$. In contrast, in Fig. 16(b) the coating residues cover an area portion of 56\%. The related adhesion strength for the coating with $1 \%$ residue after the PAT test is $12 \mathrm{MPa}$, and the coating residue of $56 \%$ corresponds to an adhesion strength of $51 \mathrm{MPa}$. The diagram in Fig. 17 depicts the adhesion strength as a function of the coating surface area remaining on the substrate after the PAT measurement. It is known from the literature that in addition to the interaction of the individual splats with each other (cohesive strength), adhesion also depends on the interaction between the splats and the substrate (adhesive strength) (Ref 29). This surface feature shows that the adhesive strength of the thermal-sprayed coating increases with a rising surface area that is covered by remaining coating on the substrate. It indicates that the proportion of metallurgical bonding between the coating and the substrate increases with the adhesion strength.

In order to obtain further information about the bonding mechanism between the coating and the substrate, the surfaces of the adhesion test spots were examined more closely. The SEM images in Fig. 18 display a detailed section of the surface of an aluminum substrate. They show the NMRP structure and parts of the coating that remained on the substrate after the adhesion test. There are areas where the substrate has been partially melted. Furthermore, dimple-like fractures can also be found on the surface of the aluminum substrate. Both features are an indication for metallurgical bonding between the substrate and the coating. Several reports point out that such fracture behavior is a characteristic of metallurgical bonding (Ref 25, 32).

The cross section in Fig. 19(a) represents a detailed portion of a measuring spot after the adhesion test. There are parts of the coating that are still bonded to the substrate. The red marked area in the light microscope image contains dark lines within the coating. Figure 19(b) shows a

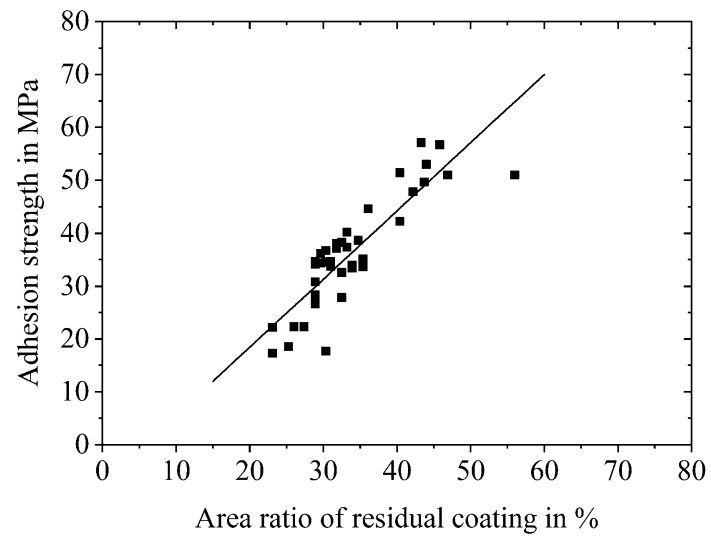

Fig. 17 Analysis of the adhesion strength as a function of the surface area ratio of the thermal-sprayed coating that remains on the substrate after adhesion strength measurement

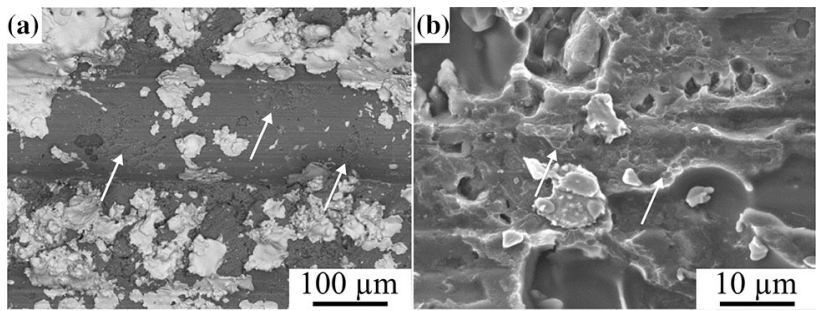

Fig. 18 SEM images displaying the surface of a coated cylinder bore after an adhesion strength test. (a) Overview of the substrate (dark) and coating (bright). (b) Detailed view with dimple-like fractures and partially melted zones

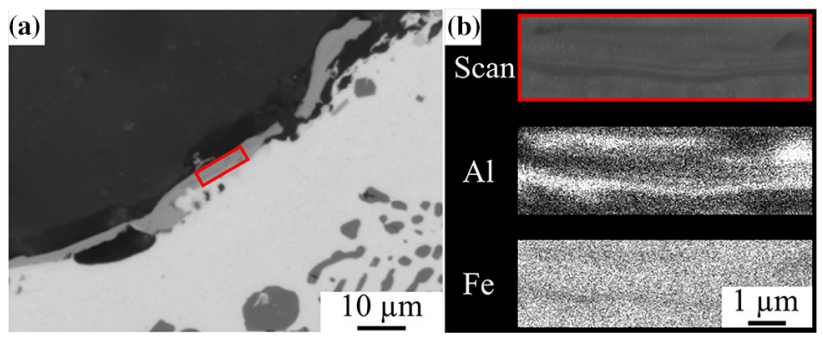

Fig. 19 (a) Light microscope image of a cross section after adhesion strength test, (b) SEM image analysis and EDS scans of the coating (red marked area) to map the element distribution of aluminum and iron within the coating

SEM image (Scan) of the red highlighted section in order to get a more detailed view. The dark lines in the splat also appear in the SEM image. The EDS scan in Fig. 19(b) visualizes the element distribution of aluminum $(\mathrm{Al})$ and iron $(\mathrm{Fe})$ within the coating. The study of the element distribution indicates that there is an accumulation of aluminum in the dark lines. The EDS mapping of the marked area illustrates that diffusion of aluminum into the thermally sprayed layer took place. The diffusion of elements from the substrate into the coating is a further confirmation of metallurgical bonds developed between the substrate and 
the coating during thermal spraying process of cylinder bores (Ref 25).

The coating adhesion is influenced by the proportion of metallurgical bonding with the substrate. This bonding mechanism is in turn influenced by oxide layers because oxide films act as diffusion barriers between the substrate and the coating (Ref 29,33,34). The presence of oxygen during the coating process leads to an oxidation of the spray particles. This causes the formation of oxide films within the microstructure and at the interface between the substrate and the coating. Therefore, oxygen during the coating process and solidification of the spray particles is also not beneficial for the development of metallurgical bonding. The results from the analysis indicate that with a low oxygen content during the coating process, there is a greater proportion of metallurgical bonding. Thus, the adhesion strength for the coating of cylinder bores with an extraction velocity of $2 \mathrm{~m} / \mathrm{s}$ increases strongly in plane 3 and plane 4. Since oxides can act as a barrier for metallurgical bonding between the coating and the substrate, the formation of the oxide layer on aluminum is investigated. XPS measurements show that an approximately 5-nm-thick oxide film forms on the surface of an aluminum crankcase for an exposure time of $20 \mathrm{~min}$ in ambient air at room temperature. A longer exposure $(45 \mathrm{~min})$ at $130{ }^{\circ} \mathrm{C}$ shows no significant effect on the oxide layer thickness. It is reported in the literature that a natural oxide layer with a thickness of about $4 \mathrm{~nm}$ grows spontaneously on aluminum (Ref 35,36$)$. Therefore, the influence of substrate oxidation is not further investigated within this study, since the thickness of the oxide layer remains almost unchanged.

Figure 20 schematically shows the adhesion mechanism for coating in an atmosphere with a high and a low oxygen content. In case of a high oxygen content within the coating system, almost only mechanical interlocking (macro and micro level) between the layer and the roughened substrate

Coating in atmosphere with high oxygen content

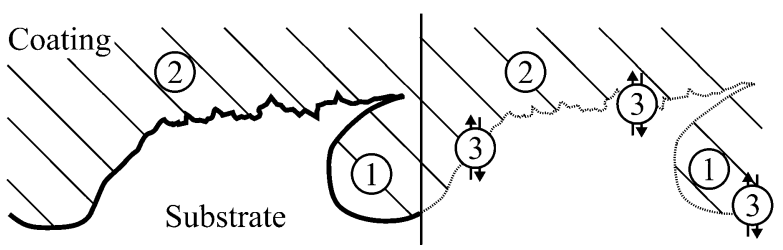

(1) Mechanical interlocking (macro)

(2) Mechanical interlocking (micro)

(3) Metallurgical bonding

Fig. 20 Schematic representation of the adhesion mechanism for coating in an atmosphere with high (left) and low (right) oxygen content. (1) Mechanical interlocking (macro), (2) mechanical interlocking (micro), (3) metallurgical bonding occurs. If there is a low oxygen concentration in the cylinder bore, metallurgical bonding between the coating and the substrate occurs more frequently. This additional adhesion mechanism probably leads to the higher adhesion strength values.

\section{Coating Approaches to Enhance the Adhesion Strength of Thermal-Sprayed Cylinder Bores}

The results of the CFD simulations and the microstructural studies indicate that the oxygen content during the coating process has an influence on the adhesion strength of the coating. An improvement of the adhesion strength in the upper and lower areas of the cylinder bore can be achieved by reducing the gap between the upper mask and the burner. A plate cover was applied on top of the mask during the coating process, which reduced the distance between the burner and the mask opening by $7 \mathrm{~mm}$. The results of the adhesion tests are shown in Fig. 21. The adhesion strength of the coating produced with the covered mask could be increased in plane $2(40 \mathrm{~mm})$ by $67 \%$ and in plane $5(130 \mathrm{~mm})$ by $35 \%$ in comparison with the coating without the mask cover $(2 \mathrm{~m} / \mathrm{s}$ extraction velocity). In order to determine the change of the oxygen content due to the mask cover, the $\mathrm{O}_{2}$ volume fraction was measured through the upper mask. The coating system was run in a test mode for the measurement to simulate the coating process without an arc. The mean oxygen volume fraction for the mask without the cover is $13 \mathrm{vol} . \%$ and $3 \mathrm{vol} . \%$ for the mask with the plate cover.

By decreasing the oxygen content due to the reduction in the gap between the mask opening and the burner, the adhesion strength in plane 2 and plane 5 can be improved. The adhesion strength in the middle of the cylinder bore (plane 3 and 4) has almost the same high adhesion level as

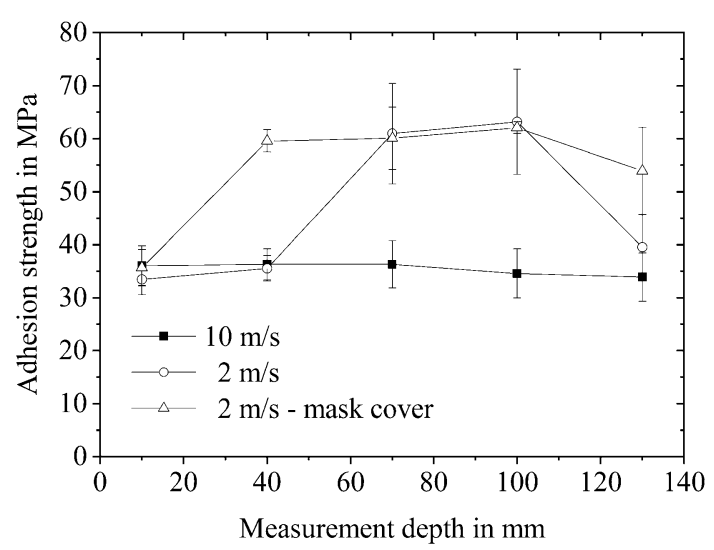

Fig. 21 Adhesion strength as a function of the position in the cylinder bore for various extraction velocities and for a special mask configuration to create a small gap between the burner and the mask opening 


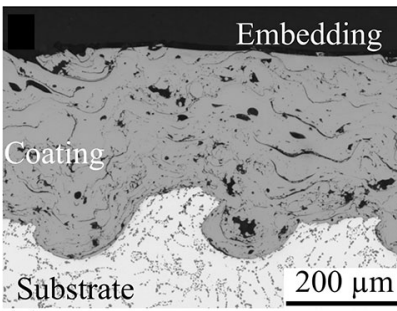

(a)

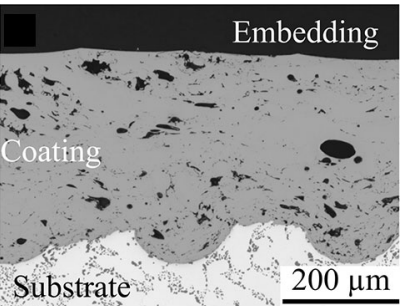

(b)

Fig. 22 Light microscope images of cross sections from twin wire arc sprayed coatings with mask cover and extraction velocity $2 \mathrm{~m} / \mathrm{s}$ at position (a) $10 \mathrm{~mm}$ and (b) $40 \mathrm{~mm}$

for the mask without the cover at an extraction velocity of $2 \mathrm{~m} / \mathrm{s}$. This result of the measurement demonstrates that the adhesive strength could be increased in $75 \%$ of the length of the cylinder bore. The two cross sections in Fig. 22 show the upper position of the cylinder bore coated with the mask coverage. The first position $10 \mathrm{~mm}$ (Fig. 22a) below the cylinder head sealing surface reveals a clear characteristic of the splat boundaries similar to the cross sections in Fig. 10.

The proportion of lamellar structures in the layer is $3.6 \% \pm 0.2 \%$ at position $10 \mathrm{~mm}$ (Fig. 22a). In comparison, the position $40 \mathrm{~mm}$ (Fig. 22b) shows a layer structure in which the individual splats are better connected to each other. The area covered by the elongated microstructures is $1.7 \% \pm 0.3 \%$. This is in analogy with the cross section at position $100 \mathrm{~mm}$ from Fig. 12(b) (proportion of lamellar structure $1.4 \% \pm 0.3 \%$ ). The further positions along the cylinder bore $(70 \mathrm{~mm}, 100 \mathrm{~mm}$ and $130 \mathrm{~mm})$ also have a proportion of lamella structures less than $2 \%$. Compared to the coating without mask cover at an extraction velocity of $2 \mathrm{~m} / \mathrm{s}$, the lamellar structures could be reduced by $60 \%$ at position $40 \mathrm{~mm}$ and $40 \%$ at position $130 \mathrm{~mm}$. The analysis reveals that coating with a mask cover leads to a more homogeneous layer structure along the length of cylinder bore in the bottom and top section because of the reduced oxygen content in the spraying atmosphere. Figure 23 displays the comparison between the adhesion strength and the area of lamellar structure within the coating along the cylinder bore. The results show the same behavior as in the coating experiment without the mask cover (Fig. 15). Areas with low adhesion strength contain more interfaces than areas with high layer adhesion, which present a more homogeneous structure.

The results demonstrate that there is still a local dependence of the oxygen content during the coating process within the cylinder bore as illustrated in Fig. 8 that influences the coating properties, the layer structure and the adhesion mechanisms mostly in the top position right below the cylinder head sealing surface. As mentioned at the beginning of "Results and Discussion" section, this

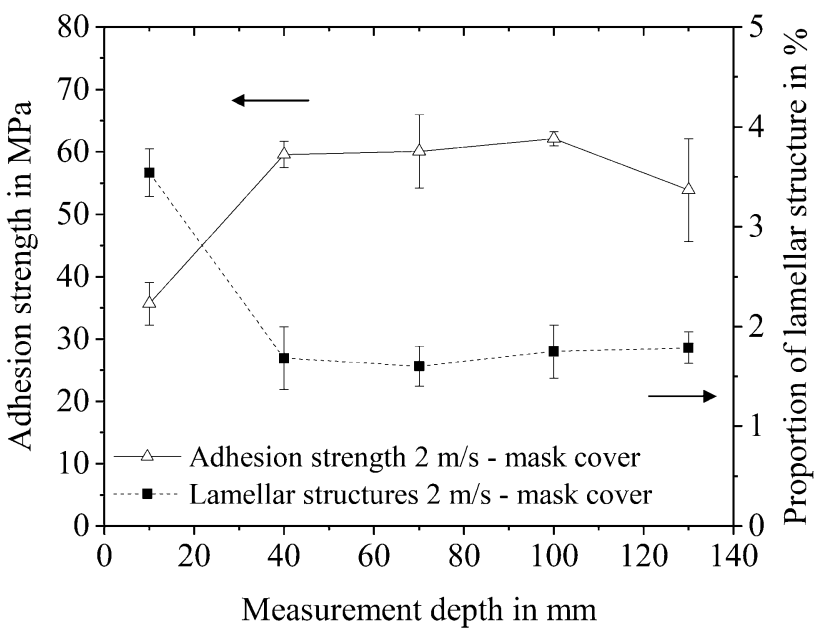

Fig. 23 Adhesion strength and proportion of lamellar structures in the coating as a function of the position in the cylinder bore for coating with a mask cover (extraction velocity: $2 \mathrm{~m} / \mathrm{s}$ )

area is close to the turning point of the piston rings where the high loads occur during operation of internal combustion engines. Therefore, further investigations on the coating process and the coating system (burner, mask, etc.) are necessary to enhance the adhesion strength especially in the upper area of the cylinder bore.

In comparison with the literature (Ref $18,37,38)$, the quality feature adhesion strength could be improved by a combination of CFD simulations to display the complex gas flow during the coating process and by various microstructural analysis to gain insights into the layer structure and the bonding mechanism (Fig. 24). The durability of the coating to layer delamination from the aluminum crankcase or to layer chipping, which can occur during processing of the coatings or during the operation of the internal combustion engines, is further improved by a higher adhesion and cohesion strength of the coating.

\section{Conclusion}

In this paper, the latest research and development activities in the field of internal diameter coating for passenger car engines were presented. Simulative and experimental investigations in thermal spray coating of cylinder bores have been carried out.

Several coating experiments demonstrated that the extraction velocity influences the adhesion strength of the coating. A reduction in the extraction velocity leads to an increase in the adhesion strength. The improvement in coating adhesion appeared locally along the cylinder bore. The CFD simulation results reveal that the oxygen mass fraction within the cylinder bore depends on the extraction velocity and the position of the burner. High extraction 


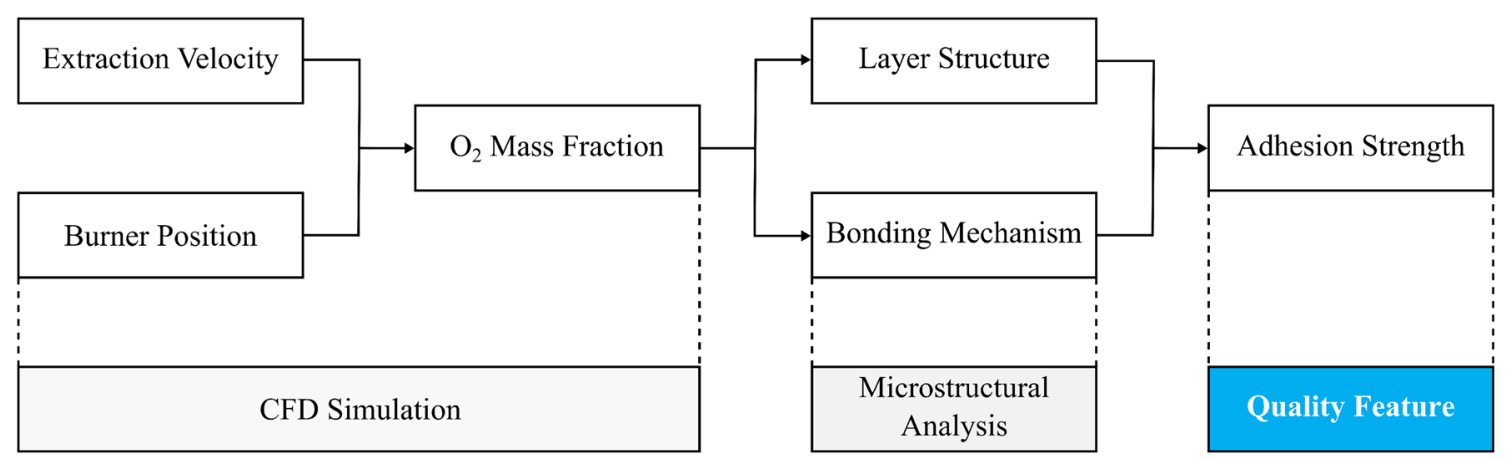

Fig. 24 Flowchart to represent the dependence of the coating properties, especially the quality feature adhesion strength through the coating process

velocities draw a large amount of ambient atmosphere into the cylinder bore. At low extraction velocities, the simulations show almost no oxygen during the coating process in the areas of high adhesive strength. In contrast, the influence of oxygen on the coating process can be identified in the areas with the lower layer adhesion.

The investigation of the microstructure showed that in the top area of the cylinder bore with the low adhesion strength, almost the same layer structure exists, independent of the extraction velocity. The coatings contain a considerable amount of oxides between the individual splats. In the area with the high coating adhesion, however, the layer structure is more homogeneous with a smaller level of oxides at the interfaces between the splats. The study of the interaction between the coating and the substrate reveals that the percentage of coating that remains on the substrate after the adhesion test increases with increasing adhesion strength. This indicates that with increasing adhesion strength, the proportion of metallurgical bonding between the substrate and the coating grows. Furthermore, partially melted zones and dimple-like fractures could be found on the substrate surface which also suggest metallurgical bonding. In addition, diffusion of aluminum from the substrate into the coating could be detected. This is a further evidence for this bonding mechanism.

The results in this paper indicate that the properties of the coating, in particular the coating adhesion, depend on the oxygen content during the coating process. Coating in an environment with a low oxygen content enhances the cohesion strength of the coating and increases the percentage of metallurgical bonding which, together with mechanical interlocking, influence the adhesion strength of the coating. These dependencies caused by the complex gas flow within the cylinder bore are special characteristics of internal diameter coating.

In order to achieve the highest quality standards, the advances of this study have already been implemented in the production of Mercedes-Benz Cars. Further research and development will be done to increase the adhesion strength along the entire cylinder bore to continuously improve the quality.

Acknowledgments This study was carried out as part of a research and development project at Mercedes-Benz AG. The authors would like to thank for the intensive and interdisciplinary cooperation.

\section{References}

1. P. Moriarty and D. Honnery, Global Transport Energy Consumption, Alternative Energy and Shale Gas Encyclopedia, J.H. Lehr and J. Keeley, Ed., Wiley, New Jersey, 2016, p 651-656

2. R.M. González, G.A. Marrero, J. Rodríguez-López, and Á.S. Marrero, Analyzing $\mathrm{CO}_{2}$ Emissions From Passenger Cars in Europe: A Dynamic Panel, Energy Policy, 2019, 129, p 12711281

3. Setting Emission Performance Standards for New Passenger Cars as Part of the Community's Integrated Approach to Reduce $\mathrm{CO}_{2}$ Emissions from Light-Duty Vehicles. Regulation (EC) No. 443/2009, European Parliament and the Council of the European Union, 2009

4. Setting $\mathrm{CO}_{2}$ Emission Performance Standards for new Passenger Cars and for New Light Commercial Vehicles, and Repealing Regulations (EC) No 443/2009 and (EU) No 510/2011. Regulation (EC) No. 631/2019, European Parliament and the Council of the European Union, 2019

5. US Energy Information Administration (EIA), Global Transportation Energy Consumption: Examination of Scenarios to 2040 using ITEDD, U.S. Department of Energy, Washington, 2017

6. K. Holmberg and A. Erdemir, $\mathrm{CO}_{2}$ Emission Globally and in Combustion Engine and Electric Cars, Tribol. Int., 2019, 135, p 389-396

7. M. Schmidt, H. Spieth, C. Haubach, C. Kühne, and NANOSLIDE ${ }^{\circledR}$ Process Chain, 100 Pioneers for Efficient Resource Management, Springer, Berlin, 2019, p 454-457

8. K. Holmberg, P. Andersson, and A. Erdemir, Global Energy Consumption Due to Friction in Passenger Cars, Tribol. Int., 2012, 47, p 221-234

9. J. Schommers, H. Scheib, M. Hartweg, and A. Bosler, Minimising Friction in Combustion Engines, MTZ Worldwide, 2013, 74(7-8), p 28-35

10. V.W. Wong and S.C. Tung, Overview of Automotive Engine Friction and Reduction Trends: Effects of Surface, Material and Lubricant-Additive Technologies, Friction, 2016, 4(1), p 1-28 
11. J. König, M. Lahres, and O. Methner, Quality Designed Twin Wire Arc Spraying of Aluminum Bores, J. Therm. Spray Technol., 2014, 24(1-2), p 63-74

12. M. Hahn and A. Fischer, Characterization of Thermal Spray Coatings for Cylinder Running Surfaces of Diesel Engines, $J$. Therm. Spray Technol., 2010, 19(5), p 866-872

13. K. Bobzin, M. Öte, and T. Königstein, Effect of Different Atomization Gases on the Properties of Cylinder Bore Coatings, Adv. Eng. Mater., 2018, 21(2), p 1800853

14. U. Morawitz, J. Mehring, and L. Schramm, Benefits of Thermal Spray Coatings in Internal Combustion Engines, with Specific View on Friction Reduction and Thermal Management, SAE Tech. Pap. Ser., 2013, 2013-01-0292

15. G. Flores, Process Chain for the Manufacture of Thermally Coated Cylinder Bores, Thermal Spray Bulletin, 2011, 4(1), p 3539

16. W. Hanke, N. Iijima, J. Müller, and M. Voigt, Friction Reduction in Power Cylinder Systems of Commercial Vehicle Engines, MTZ Worldwide, 2019, 80(2), p 18-23

17. L. Aubanel, L. Lefeivre, F. Delloro, M. Jeandin, and E. Sura, Cold Spray Coatings for Automotive Cylinder Block Application, Proceedings of the International Thermal Spray Conference New Waves of Thermal Spray Technology for Sustainable Growth, F. Azarmi, Y. Lau, J. Veilleux, C. Widener, F. Toma, H. Koivuluoto, K. Balani, H. Li, and K. Shinoda, Ed., ASM International, Yokohama, 2019, p 433-440

18. G. Barbezat, Advanced Thermal Spray Technology and Coating for Lightweight Engine Blocks for the Automotive Industry, Surf. Coat. Technol., 2005, 200(5-6), p 1990-1993

19. P.L. Fauchais, J.V. Heberlein, and M. Boulos, Thermal Spray Fundamentals: From Powder to Part, Springer, New York, 2014, p 1352-1394

20. A. Manzat and R. Gadow, Friction Reduction with Thermally Sprayed Cylinder Liner Coatings, Springer Vieweg, Wiesbaden, Reibungsminimierung im Antriebsstrang, 2018, p 217-232

21. Round Wire Rod for Welding Filler Metals. DIN 17145, German Institute for Standardization (DIN), 1980, pp. 1-9

22. K. Bobzin, M. Öte, T. Königstein, K. Dröder, H.-W. Hoffmeister, G. Mahfeld, and T. Schläfer, Development of Novel Fe-Based Coating Systems for Internal Combustion Engines, J. Therm. Spray Technol., 2018, 27(4), p 736-745

23. S. Deshpande, S. Sampath, and H. Zhang, Mechanisms of Oxidation and its Role in Microstructural Evolution of Metallic Thermal Spray Coatings-Case Study for Ni-Al, Surf. Coat. Technol., 2006, 200(18-19), p 5395-5406

24. V.V. Sobolev and J.M. Guilemany, Effect of Oxidation on Droplet Flattening and Splat-Substrate Interaction in Thermal Spraying, J. Therm. Spray Technol., 1999, 8(4), p 523-530

25. X. Wang, J. Heberlein, E. Pfender, and W. Gerberich, Effect of Nozzle Configuration, Gas Pressure, and Gas Type on Coating Properties in Wire Arc Spray, J. Therm. Spray Technol., 1999, 8(4), p 565-575
26. Q. Wei, Z. Yin, and H. Li, Oxidation Control in Plasma Spraying NiCrCoAlY Coating, Appl. Surf. Sci., 2012, 258(12), p 50945099

27. G. Jandin, H. Liao, Z.Q. Feng, and C. Coddet, Correlations Between Operating Conditions, Microstructure and Mechanical Properties of Twin Wire Arc Sprayed Steel Coatings, Mater. Sci. Eng., 2003, 349(1-2), p 298-305

28. A.P. Newbery and P.S. Grant, Oxidation During Electric Arc Spray Forming of Steel, J. Mater. Process. Technol., 2006, 178, p 259-269

29. I. Gedzevicius and A.V. Valiulis, Analysis of Wire Arc Spraying Process Variables on Coatings Properties, J. Mater. Process. Technol., 2006, 173(1-3), p 206-211

30. N. Zeoli, S. Gu, and S. Kamnis, Numerical Simulation of InFlight Particle Oxidation During Thermal Spraying, Comput. Chem. Eng., 2008, 32(7), p 1661-1668

31. J.A. Gan and C.C. Berndt, Review on the Oxidation of Metallic Thermal Sprayed Coatings: A Case Study with Reference to Rare-Earth Permanent Magnetic Coatings, J. Therm. Spray Technol., 2013, 22(7), p 1069-1091

32. C. Chen, Y. Xie, R. Huang, S. Deng, Z. Ren, and H. Liao, On the Role of Oxide Film's Cleaning Effect into the Metallurgical Bonding During Cold Spray, Mater. Lett., 2018, 210, p 199-202

33. J. Wang, C.-J. Li, G.-J. Yang, and C.-X. Li, Effect of Oxidation on the Bonding Formation of Plasma-Sprayed Stainless Steel Splats onto Stainless Steel Substrate, J. Therm. Spray Technol., 2017, 26(1-2), p 47-59

34. G.H. Meng, B.Y. Zhang, H. Liu, G.J. Yang, T. Xu, C.X. Li, and C.J. Li, Vacuum Heat Treatment Mechanisms Promoting the Adhesion Strength of Thermally Sprayed Metallic Coatings, Surf. Coat. Technol., 2018, 334, p 102-110

35. T. Campbell, R.K. Kalia, A. Nakano, and P. Vashishta, Dynamics of Oxidation of Aluminum Nanoclusters Using Variable Charge Molecular-Dynamics Simulations on Parallel Computers, Phys. Rev. Lett., 1999, 82(24), p 4866-4869

36. E. Ghali, Aluminum and Aluminum Alloys, Uhlig's Corrosion Handbook, 3rd ed., R.W. Revie, Ed., Wiley, New Jersey, 2011, p 715-745

37. K. Bobzin, F. Ernst, J. Zwick, T. Schlaefer, D. Cook, K. Nassenstein, A. Schwenk, F. Schreiber, T. Wenz, G. Flores, and M. Hahn, Coating Bores of Light Metal Engine Blocks with a Nanocomposite Material Using the Plasma Transferred Wire Arc Thermal Spray Process, J. Therm. Spray Technol., 2008, 17(3), p 344-351

38. I. Lee, H. Park, J. Kim, and C. Lee, Correlation of Microstructure with Tribological Properties in Atmospheric Plasma Sprayed Moadded Ferrous Coating, Surf. Coat. Technol., 2016, 307, p 908914

Publisher's Note Springer Nature remains neutral with regard to jurisdictional claims in published maps and institutional affiliations. 